\title{
A POÉTICA DOS TEMPOS MORTOS: diálogos entre o cinema e o videogame
}

\section{THE POETICS OF DOWNTIME: conversations between cinema and videogames}

\author{
Renata GOMES ${ }^{1}$
}

Resumo: O presente trabalho cria um diálogo entre cinema e videogames narrativos a partir das maneiras como os games ao mesmo tempo realizam e se desviam do projeto poético do cinema canônico e de como este é influenciado pelas estratégias narrativas de um certo universo de games. Para tanto, propõe-se uma atualização do conceito de narrativa, a partir da qual é possível pensar os games como uma espécie de experiência narrativa. Sob esta perspectiva, o trabalho foca a "poética dos tempos mortos", definidores das mais potentes narrativas nos games e também presentes em alguns filmes contemporâneos, influenciados direta e indiretamente por estes, compondo, portanto, uma ecologia audiovisual na qual a importância dos games é vital.

Palavras-chave: Narrativa; Cinema; Videogames.

Abstract: This paper draws a comparison between cinema and narrative videogames, anchored on the ways in which games both fulfill and deviate from cinema's poetic project and on how the later is influenced by the narrative strategies put for by videogames. To accomplish that, I propose an update to the concept of narrative that would allow us to think about videogames as a kind of narrative experience. Under this perspective, this work focuses on the "poetics of downtime", which defines narrative videogames, but that is also at play in some contemporary movies that are influenced by games and, in that, compose an audiovisual ecology in which the presence of games is vital.

Keywords: Narrative; Cinema; Videogames.

Professora Adjunta do CECULT, Centro de Cultura, Linguagens e Tecnologias Aplicadas da UFRB. Mestre e doutora em Comunicação e Semiótica pela PUC-SP, com pesquisa sobre games e narrativa. A tese de doutorado intitulada Agentes Verossímeis recebeu menção honrosa no Prêmio Capes de Teses no ano de 2009. renatafgomes@ufrb.edu.br. 


\section{míDiA

\section{Introdução: Entrar no filme}

O diálogo entre cinema e games nem sempre foi fato inegável como é hoje. Antes do surgimento de Myst (Cyan) e Doom (id Software), em 1993, a associação entre os dois universos era distante. Games eram vistos como entretenimento pueril, tinham baixíssima ou nenhuma narratividade e sua linguagem visual remetia muito mais aos quadrinhos do que ao cinema. Myst e Doom são marcos do início de uma tradição de games em ambientes virtuais tridimensionais ${ }^{2}$, narrativamente contextualizados e visualmente ancorados num expediente visual nascido no cinema canônico: a câmera subjetiva. Com seu surgimento, foi como se, de repente, começasse a se realizar um desejo antigo do espectador de cinema: o de entrar no filme, como um de seus personagens. E, se ainda hoje a relação com o cinema não é, de forma alguma, o único viés para se compreenderem os videogames, é inegável que esse entrar-no-filme inaugurou um novo e complexo universo de possibilidades, que, mais de 20 anos depois, continua sendo intensamente explorado nos games.

Assim, em que pese ser um franco herdeiro do cinema canônico, se, mais do que apenas assistir ao início de um jogo como, por exemplo, Red Dead Redemption (Rockstar San Diego, 2010), o leitor se propuser a jogá-lo, poderá perceber que se trata de algo já bastante diferente de um filme. Ao nos colocar no jogo através de um personagem, obrigando-nos a agir, como condição essencial para que o jogo exista - o jogo é um "ser-jogado" (GADAMER, 2002) -, o videogame começa a criar uma forma narrativa audiovisual autônoma, cuja característica principal é a capacidade de agenciar seu interator, chancelando-lhe "o poder satisfatório de exercer ações significativas e observar o resultado de [suas] decisões e escolhas"(MURRAY, 2003, p. 126). Em outras palavras, num game como Red Dead Redemption, em vez de apenas assistir à jornada do cavaleiro solitário, o interator vive vicariamente esse personagem, agindo no mundo da história "fisicamente" através dele. Esse tipo de agenciamento, que dá ao interator a possibilidade de fazer parte da história, constitui o principal material narrativo dos

\footnotetext{
2 É importante deixar claro que estamos nos referindo a computação gráfica que simula três dimensões na navegação do ambiente e não do 3D estereoscópico, o qual, a partir de óculos especiais, gera a sensação óptica de profundidade, com objetos que "saltam" da tela.
} 


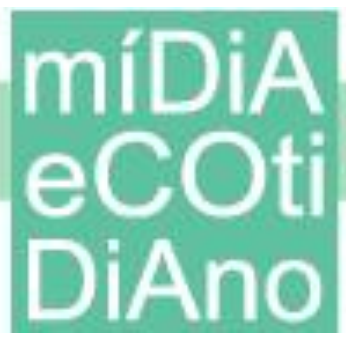

videogames, sendo muito mais importante do que suas sequências pré-editadas de vídeo, às quais o jogador assiste, sem possibilidade de interação. Essas sequências, junto com materiais textuais, dão o contexto narrativo geral, mas não contribuem majoritariamente para aquilo que acreditamos ser o verdadeiro potencial narrativo do game. O que importa, realmente, se queremos entender os games como uma forma narrativa emergente, é a experiência em si do jogo, que "implica um certo tipo de 'atuação cinestésica', que se converte num fim em si mesma” (DARLEY, 2000).

É essa atuação cinestésica - que está relacionada à jogabilidade - a característica mais fundamental do game, que o define como formato mais geral, perpassando todos os seus gêneros. Contudo, quando chega ao universo de jogos com pretensão narrativa explícita, essa característica, que, num primeiro olhar, separaria o game do cinema, parece-nos iniciar um certo movimento de imersão emocional muito afim daquele que define o cinema canônico. Nesse universo, um passo além de nos projetarmos nos personagens, somos parte do mundo ficcional, agimos e, assim, manipulamos em primeira mão a teia de causa-e-efeito que caracteriza as formas narrativas. Vivemos vicariamente uma experiência narrativa.

No entanto, como consequência direta do agenciamento do jogador como personagem da história, emerge o principal dilema dos games narrativos, sobretudo quando colocados em relação ao cinema canônico: como fazer com que o enredo seja envolvente, coeso e coerente, se quem passará a guiar o fluxo dos acontecimentos é o jogador? Essa questão está na pauta do dia dos games e ainda não foi respondida de forma definitiva (se é que isso é possível ou sequer desejável). A tentativa de resolvê-la a contento, entretanto, tem proporcionado caminhos interessantes, ainda que nem sempre consoantes.

Um primeiro caminho tenta resolver o problema de coerência narrativa pela "força bruta", ou seja, pela escritura a priori da maior quantidade possível de desdobramentos do enredo, a partir de pontos nodais de escolha do personagem-jogador. Por serem escritos um por um, tal qual um roteiro de cinema exponencialmente mais complexo, conseguem garantir que as escolhas do jogador resultem num caminho coerente e minimamente interessante. Um exemplo que leva essa estratégia aos estertores é Heavy 


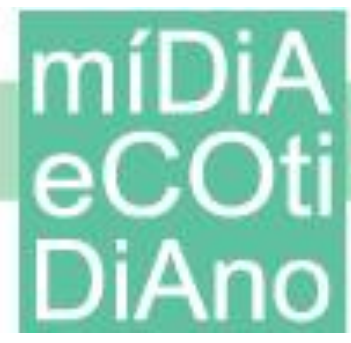

Rain (2010), um game que aceita a alcunha de "filme interativo", dada a maneira como negocia sua fronteira entre videogame e cinema. Fruto de um roteiro de cerca de duas mil páginas, com mais de 40 mil linhas de diálogos (BRAMWELL, 2008), Heavy Rain proporciona a seus jogadores uma experiência intensa, uma vez que requer deles empenho na reação imediata aos acontecimentos e a escolha das ações dos personagens, pois cada ação implicará uma bifurcação na história. O jogador é obrigado a seguir o arco narrativo principal o tempo inteiro, pois há muito nele que exige sua atenção e, fora do arco narrativo, não há nada de mais.

Nesse cenário, entra em cena uma característica que o cinema explora apenas tematicamente - em filmes como Corra Lola Corra (1998), de Tom Tykwer, por exemplo - a possibilidade de se voltar atrás nas decisões e seguir por um novo caminho, seja numa mesma sessão do game, seja numa nova, reiniciada do começo com o objetivo exclusivo de explorar novos caminhos no jogo. Contudo, justamente porque a combinação de caminhos e finais diferentes é grande, há também quem diga que não é nem divertido, nem interessante refazer o jogo exaustivamente, em busca de todos os desfechos possíveis. A sensação de agenciamento, numa estrutura como a de Heavy Rain, acaba um pouco esvaziada, uma vez que, para levar adiante a história, é preciso reagir o tempo inteiro aos acontecimentos, respondendo a comandos que aparecem na tela, seja pressionando teclas específicas num curto intervalo de tempo, seja escolhendo de um menu de opções a reação do personagem. O jogar, em Heavy Rain, é cortado todo o tempo por cenas pré-editadas, que, embora tenham transição imperceptível em relação ao jogo, ainda assim distanciam o jogador da posição de personagem-agente, retornando-o à posição de espectador. Nessa dinâmica, percebe-se que todos os desfechos da história existem a priori e são relativamente arbitrários; a escolha do jogador apenas atualiza algo que era virtual, num escopo razoavelmente previsível. Mais: reproduzindo o mesmo tipo de narratividade do cinema de enredo bem amarrado, mas agora em escala exponencial, alguns caminhos serão mais gratificantes, enquanto outros serão necessariamente mais frustrantes, dramaticamente falando.

Em outra frente, em vez de se preocupar em criar, a ferro e fogo, "veredas que se bifurcam" (como nos propôs Jorge Luis Borges), jogos de personagem com arquitetura 


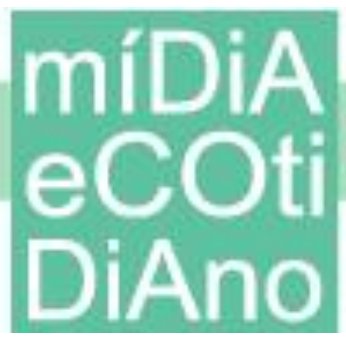

mais sistêmica focam esforços na criação de um universo aberto, que responda às ações do jogador de forma "viva". Tal gênero já atende pelo nome de sandbox, que faz alusão à caixinha de areia onde brincam as crianças, na qual é possível inventar a própria maneira de brincar. Tais games oferecem ao jogador uma linha narrativa mais linear, sem muitas bifurcações, mas, paralelamente a esta, ofertam também um mundo mais aberto, que o jogador pode habitar numa gama mais vasta de interações possíveis, não apenas com o ambiente, mas também com sua ecologia de agentes, entre personagens humanos e animais. A ideia, nesses casos, é criar um mundo cuja possibilidade de imersão e de presença seja reiterada todo o tempo pela complexidade e autonomia de sua constituição. Mesmo que isso não seja diretamente importante para o arco narrativo principal do jogo, é possível, no corpo do personagem, navegar por todo o mundo do jogo, por quanto tempo se quiser - seja ele uma cidadela da Idade Média, o faroeste americano ou um clone assumido de Los Angeles ou Nova Iorque - interagindo com seus objetos e agentes da forma mais intuitiva possível.

\section{Ser o personagem}

Não por acaso, este é o caminho seguido por Red Dead Redemption, um game de personagem que se passa num mundo vasto e complexo, o qual penetramos na "pele" de John Marston, vivendo a dor e a delícia de ser um cowboy no faroeste americano, cheio de bandidos, mocinhos, mocinhas, indígenas e feras. Como Marston, é possível seguir as missões propostas pelo jogo - que formam seu arco narrativo principal - ou ignorálas, quando quisermos vagar pelo mundo como bem entendermos. Mesmo se optarmos por seguir o arco narrativo principal, a execução das missões obriga a exploração mais livre do mundo do jogo e uma relação mais complexa com este. A ênfase no arco narrativo é diminuída e a experiência em si do jogador como protagonista se torna mais relevante. Ser o protagonista deste jogo implica, antes e acima de qualquer outra coisa, penetrar seu espaço-tempo através de um corpo. Em outras palavras: "ser" John Marston é controlar o corpo de um cowboy em diversos tipos de ambiente, aprendendo a fazê-lo andar, correr, pular, atirar, montar a cavalo, entre outras ações motoras, da forma mais eficiente possível. De outra forma mundanas, no game, são essas ações que 
fazem a "mágica" de nos ancorar no mundo, profundamente identificados com o corpo que controlamos. O caso de Red Dead Redemption é emblemático: cavalgar com John Marston rumo ao pôr-do-sol, ouvindo tanto o ruído ambiente quanto a trilha sonora, é como habitar não apenas uma versão simplificada do Oeste americano do século XIX, mas o gênero do western em si mesmo. Contudo, para essa profunda sensação de imersão e presença, tão ou mais importante que o cine-realismo do ambiente, ou sua atualização do áudio, é a capacidade de controlarmos o personagem em seu cavalo, num ambiente cuja pulsação nos remete ao mundo real.

No mundo do game, esse estar-no-mundo diz respeito às capacidades de nosso corpo virtual, muito mais do que a sua sofisticação audiovisual. Dito de outra forma, teremos, no mundo de Red Dead Redemption, maior sensação de presença e, por consequência, de imersão, na medida em que nosso corpo virtual for capaz de, sob nosso comando, executar ou não determinadas ações. A compreensão dessa relação entre imersão/presença e capacidade do corpo virtual é facilitada pelo conceito de affordances: o que o ambiente oferece ao animal, para o bem ou para o mal, implicando uma complementaridade entre este e seu ambiente. Como exemplifica Gibson:

\footnotetext{
[...] se uma superfície terrestre é minimamente horizontal (ao invés de inclinada), minimamente plana (em vez de côncava ou convexa) e suficientemente extensa (em relação ao tamanho do animal) e se sua substância é rígida (em relação ao peso do animal), então, a superfície oferece suporte. É uma superfície de suporte e nós a chamamos de substrato, chão ou piso. Ela possibilita ficar de pé, permitindo uma posição ereta a quadrúpedes ou bípedes. É, portanto, "andável" e "corrível". Não é "afundável" como uma superfície aquosa ou um pântano, isto é, não para animais terrestres mais pesados [...]. Notemos que as quatro propriedades listadas - horizontal, plana, extensa e rígida - seriam propriedades físicas de uma superfície, se fossem medidas com a escala e unidades de medida padrão da física. Contudo, como possibilitam suporte a uma espécie animal, elas têm de ser medidas em relação a esse animal. (GIBSON, 1986, p. 127)
}

Ora, do ponto de vista do design e da programação, a construção de um game de personagem nada mais é que a criação de affordances, ou seja, a programação explícita do ambiente como uma série de objetos, que se comportam de modo a proporcionar ao avatar a possibilidade de navegação no mundo do jogo. No game, o chão é uma affordance desenhada para dar ao avatar - e aos demais agentes e objetos do jogo suporte. Da mesma forma, o próprio avatar é um conjunto de affordances que oferece ao 
jogador a capacidade de se compor com o objeto chão, entre outros, para poder andar, correr, saltar etc. Nesse cenário, podemos dizer que nossa percepção do mundo virtual será construída através de nosso estar-no-mundo. A percepção da dimensão de altura, por exemplo, será construída

[...] na medida em que nosso corpo virtual conseguir ou não alcançar determinados pontos verticalmente distantes no ambiente digital; a percepção de velocidade, baseada, entre outros, no intervalo de tempo em que se pode transpor um determinado percurso; a percepção de uma constante gravitacional, através do ato de caminhar, de correr, de pular e etc. Estar no mundo pela presença corporificada de um personagem constitui boa parte do que significa o jogar em si e, para cada desafio proposto, uma grande medida estará diretamente associada à possibilidade de obter do corpo que controlamos a percepção, a ação, a resposta precisa necessária para sua execução. (GOMES, 2006, p. 74)

Assim, "o corpo do avatar é a expressão direta de seu ambiente, inscrito no espaço do game com uma capacidade para suas distâncias"(OLIVER, 2001). O corpo virtual implica, portanto, uma perspectiva. Em outras palavras, é possível encarar o game de personagem como a vivência vicária de uma experiência narrativa.

\section{Experiência narrativa}

Para compreender o game de personagem como forma narrativa emergente, é preciso problematizar o próprio conceito de narrativa. Em lugar de encará-la exclusivamente como uma cadeia de causa-e-efeito finamente talhada, na qual nos projetamos, através das ações e motivações dos personagens, de modo a chegar num final catártico, é preciso ir além. Sem poder abraçar uma discussão aprofundada acerca da definição de narrativa, da maneira como tem sido proposta pela narratologia contemporânea, vamos nos ater a alguns elementos-chave que reposicionam o sentido geral desse conceito.

No mundo contemporâneo, a narrativa é compreendida como uma forma muito antiga, que emergiu nas sociedades primariamente orais como uma estratégia de reorganização da experiência (ONG, 1998, p. 158-159). Ou seja, não uma forma acabada, autoconsciente e deliberadamente artística, como nos parece hoje, mas uma forma fluida, comunal, que emergiu nas sociedades a partir da necessidade vital de, pela linguagem verbal oral, dar sentido à experiência do vivido e disseminá-la na forma de 


\section{míDiA

conhecimento. Enxergando-a como essa forma expressiva que emerge da necessidade de organizar a experiência, acreditamos que a narrativa transcende os meios que a incorporam, tendo existido mais funcionalmente na oralidade, depois evoluído e se modificado no texto manuscrito e no texto impresso, mas também, em sua forma mimética, no teatro, no cinema, na televisão, entre várias formas presentes e outras que, acreditamos, ainda hão de surgir. A cada um desses meios, a narrativa se amolda de maneira diferente, em diálogo com o contexto histórico e fazendo-se valer das características intrínsecas a cada um para criar diferentes possibilidades que, contudo, de alguma maneira, continuam reorganizando o fluxo da experiência vivida.

Marie-Laure Ryan propõe definir a forma narrativa não a partir de seu nível sintático, mas sim de seu nível semântico, ou seja, de seu conteúdo, das particularidades no nível da história. Para isso, define-a como um tipo específico de "imagem mental" que certos textos evocam (RYAN, 2007, p. 25). Essa imagem mental precisa cumprir alguns requisitos para poder ser considerada narrativa. Aqui, vamos combinar algumas características propostas por Ryan e por Herman (2009), que dialogam diretamente. Ryan nos fala que, para ser considerado narrativo, um texto deve tratar, entre outras coisas, de um "mundo habitado por indivíduos, [...] que está situado no tempo e [...] que sofre transformações, causadas por eventos físicos, não-habituais (RYAN, 2007, p. 19). Herman descreve mais ou menos as mesmas características, mas elabora uma de maneira particular, enfatizando que uma narrativa

[...] expressa a experiência de viver nesse mundo-em-fluxo, realçando a pressão dos eventos sobre consciências reais ou imaginárias afetadas pelas ocorrências em questão. Assim [...], podemos argumentar que narrativas têm como preocupação central o qualia, um termo utilizado por filósofos da mente para se referir ao sentido de "como é" para alguém ou algo ter uma experiência particular. (HERMAN, 2009, p. 137)

Herman ressalta, portanto, a dimensão de experiência da forma narrativa, chamando atenção para a importância desta como uma maneira de compreender as

(Ênfases e aspas do autor) [Original em inglês: [...] convey the experience of living through storyworlds-in-flux, highlighting the pressure of events on real or imagined consciousnesses affected by the occurrences at issue. Thus [...] it can be argued that narrative is centrally concerned with qualia, a term used by philosophers of mind to refer to the sense of 'what it is like' for someone or something to have a particular experience.] 


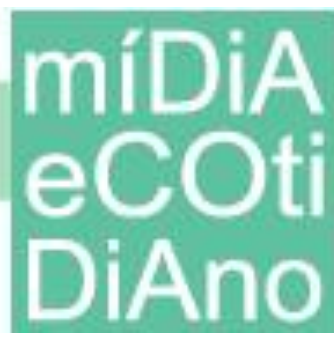

emoções e sentimentos de seus agentes enquanto as viviam. Herman refere-se, em princípio, às narrativas tradicionais, as quais, ao nos projetar em seus personagens, proporcionam-nos a inferência de suas emoções, sentimentos, desejos e objetivos. Contudo, recapitulando tudo o que construímos até aqui, é inevitável enxergar uma afinidade entre a natureza de experiência em primeira pessoa dos games de personagem e essa característica da forma narrativa apontada por Herman. Quanto às primeiras características citadas por Ryan, essas são levadas aos estertores por games como Red Dead Redemption, que constroem mundos complexos com agentes autônomos e fazem disparar acontecimentos motivados, com os quais o jogador se depara, vivendo ele mesmo a experiência de "como é" e, ao mesmo tempo, ainda se projetando nos personagens do jogo.

\section{"Como é"}

É cedo para dizer se games como Red Dead Redemption ainda podem ser chamados de narrativa, sendo apenas a mais recente corporificação dela num novo meio, ou se são uma forma "pós-narrativa", como defende Aarseth (2004), que não deve ser misturada a histórias tradicionais, sob pena de causar confusão mútua. Para nós, a narrativa é uma matriz de linguagem e pensamento (SANTAELLA, 2001) altamente inclusiva, dentro da qual cabem, sem maiores problemas, objetos como os games de personagem. Além do mais, a narrativa não é um universo ao qual ou se pertence $100 \%$ ou nada - como, ademais, a nenhum outro tipo de taxonomia. Parece-nos que é mais produtivo falar - seguindo Ryan (2007) - em graus de narratividade, ou seja, em obras e acontecimentos que dialogam mais ou menos diretamente com as características que enumeramos, estando no centro ou mais na periferia desse universo. Mas isso é menos importante do que diagnosticar o que um game como Red Dead Redemption faz, inegavelmente, enquanto experiência estética e cognitiva. Do que vamos chamá-lo mais adiante e que desdobramentos terá, o tempo dirá. Da mesma forma, também não há nenhum bom motivo para acreditarmos que, como no cinema, apenas uma forma de videogames será hegemônica, em detrimento de outras, que sobrevirão apenas na periferia - seja no circuito "de arte", seja noutros, menos nobres. A diversidade, no 


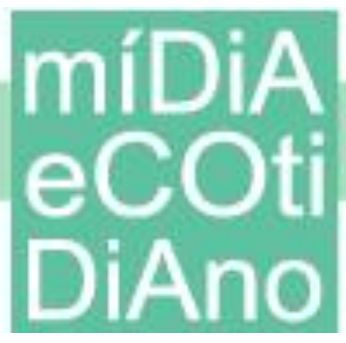

mundo dos games, é, de fato, maior que no mundo do cinema e todos esses gêneros e formatos tendem a seguir se contaminando uns aos outros, talvez jamais gerando uma forma tão sedimentada quanto o cinema canônico, por exemplo.

Dentre os games que se podem enxergar como formato razoavelmente estável, cuja dinâmica de jogo já está fortemente disseminada entre comunidade de jogadores, está, sem dúvidas, o gênero sandbox. Basta observar um jogador habituado iniciando, pela primeira vez, um novo game desse gênero: a fruição é intuitiva, tanto na operação do jogo, quanto na construção da experiência narrativa. Como na maior parte dos jogos de personagem, quando se relata a experiência de jogar, o discurso sai em primeira pessoa: "eu consegui escapar dos bandidos", "о meи cavalo morreu”, "morri". Essa experiência narrativa em primeira pessoa consiste em navegar pelo mundo do jogo, intuitivamente, buscando objetos, pessoas ou eventos de interesse, seguindo ou não os conselhos do que podemos chamar de "inteligência narrativa central", que ora vai disparar acontecimentos, ora sugerir caminhos, algumas vezes até impor ações. Mesmo quando optamos por seguir os conselhos dessa inteligência narrativa, a maneira de levar a cabo as missões propostas é bastante aberta e requer interpretação acerca dos objetivos e modos de alcançá-los. Em outras palavras, tudo o que sabemos é que devemos ir para um determinado lugar ou conseguir um determinado objeto, mas a forma de consegui-lo deve ser construída pelo jogador. Essa construção é, por definição, repleta de tentativas frustradas, caminhos tortos, sugestões ambíguas, suposições equivocadas - e, mais importante, nada disso é necessariamente um "defeito" do jogo, mas, sim, parte constitutiva desse devir de "tempos mortos" que a experiência narrativa nos dá no game, de maneira análoga à "narrativa" da vida.

Quando, logo no começo de Red Dead Redemption, por exemplo, o jogo nos aconselha a ir "conhecer o xerife", um mapa nos informa a direção que devemos tomar a caminho da cidade. Assim, montamos nosso cavalo e seguimos esse caminho, das primeiras vezes errando a rota e corrigindo-a a todo momento. Se algo de interessante aparecer no percurso, podemos, sem prejuízo ao arco narrativo central, perseguir essa nova informação, seja ela qual for, para depois voltarmos ao objetivo inicial. Muitos jogadores com frequência ignoram completamente as sugestões da narrativa, no começo 
de um novo jogo, preferindo primeiro aclimatar-se às affordances do mundo. Assim, sobretudo os mais jovens - claramente formados pela lógica operacional de tentativa-eerro dos games, muito mais do que pela teleologia da literatura ou do cinema, por exemplo - saem pelo mundo, experimentando as capacidades de seu corpo virtual e as particularidades do ambiente, sem o compromisso de seguir o arco narrativo central. Testam tudo o que podem, alheios às intenções da narrativa, pois podem, quando bem quiserem, voltar atrás, recarregar o jogo e, aí sim, começar a seguir a história, agora já acostumados ao ambiente e às próprias capacidades.

A qualidade incomparável dessa experiência em primeira pessoa é sua organicidade, proporcionada por um mundo que "existe", independente dos desígnios da narrativa central ou de nossos desejos. A combinação de nossas imprevisíveis intenções e ações à complexidade do mundo virtual gera o grande trunfo desse tipo de experiência, aquilo que só conseguimos apreender como o mais poderoso índice de "realidade" do mundo: o acaso. Ou, dito de outra forma, como a emergência repentina de um acontecimento randômico, que não foi exatamente programado para se dar ali, naquele momento, daquela forma, com você. Isso é possível, num game complexo como Red Dead Redemption, graças à sua arquitetura de programação. Não se trata, obviamente, de um Acaso, com A maiúsculo, no sentido metafísico do termo. Tudo o que existe no game foi previamente escrito por programadores e nada se gera espontaneamente, portanto, não há de fato Acaso. Contudo, a partir de uma certa escala de complexidade, combinada à ação do jogador, a possibilidade de articulações excede a nossa capacidade de previsão, gerando acontecimentos inesperados, às vezes surpreendendo até mesmo os programadores.

Assim, se, rumo à delegacia, o jogador passar um pouco mais de tempo conhecendo a vizinhança, quando finalmente se puser a caminho da cidade, poderá se deparar com um grupo de bandidos ou uma matilha de lobos, por exemplo. Esse acontecimento não foi escrito deliberadamente para acontecer naquele momento, como nos games de roteiro mais fechado, à la Heavy Rain. Tais grupos foram bater ali graças a uma certa aleatoriedade de que são dotados alguns eventos do jogo e, noutras circunstâncias - se o jogador tivesse partido para a delegacia antes, se fosse outro 


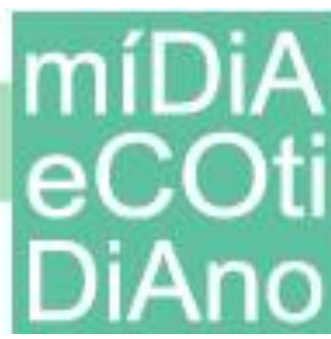

jogador, outra sessão do jogo - poderiam muito bem não estar lá. Desse encontro pode emergir - ou não - um acontecimento imprevisto e que, embora provavelmente não vá interferir no arco narrativo central, compõe a experiência narrativa do interator, gerando um "como é" - para usar o termo de Herman - pessoal e intransferível. Essa pulsão de Acaso, baseada nesses pequenos acontecimentos, permeia nosso estar-no-mundo em games como Red Dead Redemption e transformam-no numa experiência narrativa aberta, particular e menos arbitrária do que em games como Heavy Rain.

\section{Cinema $\Leftrightarrow$ Games}

Parte cada vez mais hegemônica da indústria audiovisual, rivalizando com o cinema hollywoodiano pela posição de entretenimento mais rentável, os games, obviamente, não existem no vazio. Ao contrário, compõem, com cada vez mais notoriedade, uma ampla ecologia audiovisual e são contaminados por outros formatos, como já afirmamos acerca de Red Dead Redemption. Contudo, numa ecologia sofisticada como o audiovisual contemporâneo, além de herdarem características do cinema, os games têm passado também a influenciá-lo, direta e indiretamente. Um nível dessa influência é tão obvio e caricatural quanto alguns aspectos da mimetização por Red Dead Redemption do gênero de western. Trata-se das adaptações de games para filmes (e vice-versa) ou das transposições meramente temáticas entre os dois formatos. A maior parte dos casos de adaptação de game para filme resulta em obras empobrecidas dramaticamente, meras commodities da indústria cultural, cuja razão de existir é, acima de tudo, poupar investimentos de criação de propriedade intelectual e aproveitar um público já cativo.

Certos casos são piores que outros, como a série de filmes com a personagem de games Lara Croft. Alguns dos jogos da série Tomb Raider são verdadeiros marcos da história dos games. Embora não tão complexo quanto sandboxes como Red Dead Redemption, Tomb Raider 2 (1996), um best seller de sua época, teve inúmeros méritos na criação desse estar-no-mundo a que tantos nos referimos. De tão bem desenhada, do ponto de vista da experiência espaço-temporal, uma fase do jogo em particular, que se passa em Veneza, habita até hoje a memória de seus jogadores, tendo gerado em alguns 


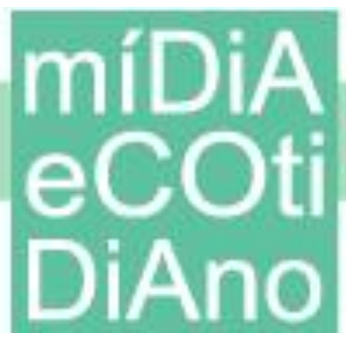

que nunca estiveram no Vêneto - como esta pesquisadora - experiências profundamente imersivas da cidade. Contudo, sua transposição para o cinema gerou dois filmes absolutamente simplórios, do ponto de vista narrativo e visual, mas bastante lucrativos, o que, certamente, explica a insistência da indústria em seguir adaptando games para o cinema. O pior problema do filme Tomb Raider (2001) jaz na tentativa de transpor diretamente para o cinema justamente o enredo dos games, ou seja, sua parte mais fraca e esquemática. Os personagens acabam sem profundidade dramática, num meio em que isso é imperdoável. E aquilo que era a razão de ser do jogo - o estar-no-mundo através do corpo de Lara Croft - perde-se em pirotecnia inútil para o espectador, que assiste ao filme, sem poder "habitá-lo" através de Lara Croft. Como bem comentou um frustrado espectador de apenas nove anos de idade, com ironia involuntária: o pior do filme é que não dá para jogá-lo.

Algumas adaptações são bem mais felizes, contudo. Silent Hill (2006), que tratou de criar um enredo mais elaborado que sua cara-metade digital, fez um filme de terror que se mantém sozinho, sem precisar ser justificado pelo game. Noutros casos, os games são apenas parte da influência, como no recente Scott Pilgrim versus The World (2010), adaptação para o cinema da obra de quadrinhos, a qual traz alguns bons insights para o filme a partir dos games. Uma forma bem particular de transposição de games para o cinema é o machinima, corruptela de "machine cinema" ou "machine animation". Trata-se de filmes lineares, não-interativos, feitos a partir de imagens capturadas diretamente de games. Noutras palavras, uma equipe de indivíduos "joga" um determinado game, visando não a experiência normal do jogo, mas a atuação de um roteiro escrito previamente. Alguns jogadores operam os personagens, outros ficam encarregados apenas da câmera virtual do jogo. As imagens dessa atuação são gravadas e, posteriormente, dubladas e editadas, transformando-se num filme de animação. Os melhores exemplares do formato, contudo, são feitos a partir da intervenção bem mais complexa na própria engine dos jogos - ou seja, do software usado para gerar o próprio game. Parte da produção de machinima tem apresentado qualidade técnica elevada e a organização desse ramo já é bem razoável, com festivais internacionais e outras formas de reconhecimento pela indústria e crítica especializada. $\mathrm{O}$ formato tende a crescer, pois 


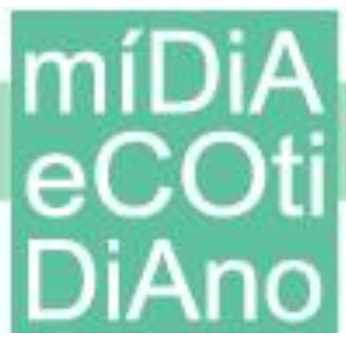

trata-se de uma maneira prática e eficiente de fazer animações. Assim, cada vez mais, geram-se curtas e longas-metragens elaborados, havendo, inclusive, um machinima baseado em Red Dead Redemption, o curta The Man from Blackwater (2010), dirigido pelo cineasta australiano John Hillcoat, feito especialmente para o lançamento do game.

O caminho contrário - do cinema para os games - cresce cada vez mais. Talvez um dos casos mais felizes seja o game Enter the Matrix (2003), baseado, como o nome indica, na série cinematográfica Matrix (1999). O jogo foi feito para compor um projeto transmídia, ao lado do $2^{\circ}$ e $3^{\circ}$ filmes da série, além da série de animação Animatrix (2003). O game traz informações narrativas que não estão nos filmes, ajudando a compor justamente esse universo transmídia, no qual cada formato - filme, série de animação e game - informa um mesmo mundo narrativo, tornando-o mais complexo para o espectador/jogador. Como sói acontecer nas franquias transmídia, as informações narrativas contidas no game - assim como na série de animação - são secundárias em relação ao que está no produto principal, os filmes. Assim, elas sofisticam a construção do mundo da história, mas a compreensão básica do enredo dos filmes não depende delas. Enter the Matrix foi um dos primeiros exemplares de uma tendência cada vez mais comum, o lançamento de blockbusters cinematográficos junto a games que os complementam (ou apenas ilustram). Um caso mais recente foi o game feito a partir do filme Avatar (2009). Enquanto o filme causou um impacto considerável no público, mas também na crítica, sobretudo por seus feitos tecnológicos - a qualidade da computação gráfica e o 3D estereoscópico - o game foi considerado "decepcionante" (BRUDVIG, 2009), segundo parte da imprensa especializada, o que não deixa de ser extremamente irônico, se considerarmos que o filme já problematizava a questão da presença corporificada, narrativizando de forma interessante um problema central aos videogames. Enquanto o filme dava cores realistas à questão da corporificação, o game transformava essa experiência em algo "mundano" (VANORD, 2009), falhando em produzir um estar-no-mundo satisfatório numa mídia em que isso é essencial.

De modo geral, contudo, o caminho de adaptação que parte dos filmes e chega aos games tem, em princípio, mais possibilidades de dar certo do que o caminho contrário. Se nada mais, um bom filme cria um mundo narrativo que é muito maior do que aquele 


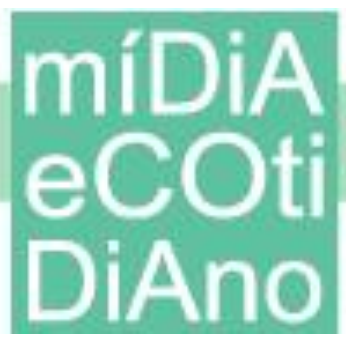

explicitamente mostrado por seu enredo. Como tem demonstrado o que já se convencionou chamar de fan fiction, o material imaginário gerado por filmes - ou livros ou séries de TV - é tão vasto que dá margem à criação de inúmeras obras paralelas, muitas inclusive feitas pelos fãs dessas histórias. Dessa forma, um game baseado no filme já recebe de antemão todo um contexto narrativo, que é o mais difícil de se criar a contento num game, pelos motivos anteriormente expostos. Assim, os games adaptados de filmes com maior êxito estético ou narrativo tentam não repetir os enredos encampados por seus antecessores, mas, sim, criar tramas paralelas, nas "brechas" do contexto narrativo geral e a explorá-las da maneira nativa aos games: como mundos a serem habitados. Um dos exemplos recentes mais felizes dessa estratégia - além do já citado Enter the Matrix - foi o game Star Wars: The Force Unleashed (2008). Embora imperfeito em sua execução técnica e criativa, o game dava ao jogador a oportunidade de ser um jedi do Lado Negro da Força. Em outras palavras, mais de 30 anos depois do lançamento do primeiro filme da série - o Star Wars original - o jogo materializou de maneira bastante particular o desejo tácito de toda uma geração de exercer os poderes jedis, como aprendiz de Darth Vader. A utilização de engine de física Euphoria proporcionou uma experiência até então inédita na manipulação de objetos, o que, aplicando-se ao poder jedi supremo - a telecinesia, poder de mover objetos à distância trouxe um grau de realismo especial à experiência do jogo.

Como tudo na ecologia cultural contemporânea, a influência mútua entre games e cinema mostra uma tendência de crescimento, modificando a própria natureza de ambos formatos, num movimento de recriação que parece agora ser perene. Neste momento, contudo, embora muitas experiências estejam sendo levadas adiante, tornando virtualmente impossível o mapeamento completo dessa influência mútua, o que podemos constatar é que poucas obras desse diálogo são de fato interessantes, do ponto de vista de seu conteúdo. Talvez porque envolvam grandes somas de dinheiro para sua realização, o que se pode perceber em relação a games-a-partir-de-filmes e filmes-apartir-de-games é que estão longe de ter o vigor que associamos à arte e às cinematografias independentes. Ao contrário, e sob a camuflagem de "transmídia", o que mais vemos, tanto em filmes quanto em games da indústria, é a repetição de 


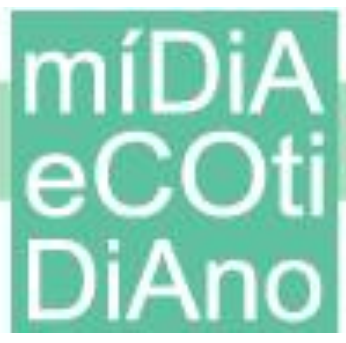

fórmulas e temas, numa infinita sucessão de franquias, consumidas e descartadas em intervalo cada vez menor, a tempo de abrir caminho para a chegada do novo grande sucesso. Nessa indústria cultural 2.0, parece ser de onde menos se espera que surge o ruído criativo a oxigenar um cenário de outra forma estéril. As mais interessantes dobras entre cinema e games geram um devir de tempos mortos, cujo diálogo pode ser enxergado em filmes nas franjas de Hollywood, nas cinematografias independentes do mundo inteiro.

\section{A poética dos tempos mortos}

Muito além do universo temático da indústria audiovisual, é possível perceber as sutis influências dos games no cenário contemporâneo do cinema. Um exemplo emblemático é o filme Elefante (2003), do diretor americano Gus van Sant e isso devese muito mais do que apenas à referência explícita aos games no enredo do filme. Elefante foi abertamente inspirado pelo massacre ocorrido na escola Columbine, no Colorado, EUA, em abril de 1999. No evento, dois garotos de cerca de 18 anos entraram na escola armados até os dentes, saíram atirando a esmo, matando e ferindo algumas dezenas de alunos e professores e, ao final, suicidaram-se. O filme conta uma história cujo desfecho é citação direta a Columbine, mas filmado em alguns momentos do ponto de vista em primeira pessoa característico de games como Doom. Na sintaxe visual desse game - um first-person shooter clássico - o que se pode enxergar na tela é um plano-sequência com a subjetiva do personagem e, de seu corpo, apenas a mão que segura uma arma de fogo (ou apenas a arma), na borda inferior da tela. Essa escolha de Van Sant, fundada em sua experiência com Tomb Raider (PEARY, 2003), foi motivo de polêmica, como tudo o que diz respeito tanto ao episódio de Columbine e aos games violentos, mas é apenas a citação mais óbvia e não a mais pertinente ao mundo dos games. Muito mais do que apenas essa relação explícita à linguagem visual dos jogos de tiro, toda a estrutura narrativa de Elefante remete a um diálogo com a construção de espaço, tempo e narrativa dos games (ainda que não apenas a isso). O filme é estruturado como a repetição momentos que antecedem o massacre em si, com a câmera seguindo personagens diferentes em longos planos-sequência, enquanto caminham 


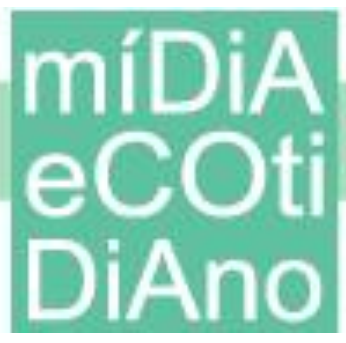

pelos corredores e outros ambientes dentro e fora da escola, em ações que não se relacionam de forma causal com os acontecimentos que virão. Van Sant explora os tempos mortos, em que "nada acontece", usando a relação dos personagens com o ambiente como nexo para a narrativa - tal qual num videogame.

Essa poética dos tempos mortos tem interessado Van Sant há um certo tempo e aqui não se trata de buscar causas fechadas para as escolhas estéticas em seus filmes - o que provavelmente não é claro nem para o próprio diretor, que, ademais, afirma ser influenciado também pelo cinema de Bella Tarr, Tarkovski e Sokurov (PEARY, 2003). O que interessa é tentar identificar alguns traços de um novo devir narrativo consoante com aquele que apontamos nos games. Nessa grande ecologia que inclui games de personagem e filmes narrativos, entre outros, começamos a perceber a emergência cada vez maior de histórias menos voltadas à confecção de um enredo exemplarmente amarrado e mais preocupadas com a construção de um espaço-tempo a ser habitado por personagens, os quais vivenciam situações ambíguas, de maneira bem mais orgânica. Essa investigação acerca de uma dramaticidade dos tempos mortos foi levada aos estertores por Van Sant em Últimos Dias (2005), que narra, quase em tempo real, os dias que antecedem a morte de um personagem baseado no músico Kurt Cobain. O filme detém-se nas mais mundanas atividades do personagem, provocando o esgarçamento do tecido narrativo quase ao limite. Em seu filme seguinte, Paranoid Park (2006), o cineasta retrocede um pouco na exploração dos tempos mortos, que, contudo, ainda têm importância marcante, junto a outra marca da narrativa dos games, a repetição (já anteriormente explorada em Elefante). Em seus filmes recentes, Van Sant parece ir testando os limites da narrativa, manipulando seus elementos individualmente, como quem busca, deliberadamente, extrair de sua combinação novas propriedades. Contudo, mesmo ao manipular em diversas intensidades esse estar-no-mundo de seus personagens, em todos os seus filmes recentes, Van Sant ainda deixa clara a tentativa de sedimentá-los como narrativa, no que esta tem de comunicativa em algum nível. Desta forma, longe de serem herméticos, seus filmes são narrativas envolventes, capazes de gerar emoção em seus espectadores. Mesmo Últimos Dias, que resvala na não- 


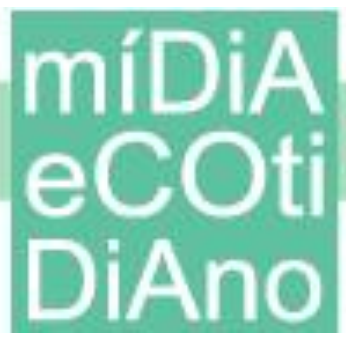

narratividade, ainda tem uma preocupação evidente com a construção dessa dimensão de "como é" a experiência do personagem face aos acontecimentos que vive.

Outros filmes se encaixam nessa ecologia de causalidade esgarçada, de narrativas ancoradas na experiência de personagens em seu ambiente, cada um explorando de maneira particular propriedades específicas da forma narrativa. Para citar alguns exemplos pontuais, $O$ Filho (2002), dos irmãos Pierre e Jean-Luc Dardenne, é visualmente estruturado de forma parecida com um game de personagem, uma vez que a câmera segue o protagonista de perto, raramente mostrando-o de frente. Porque a linguagem visual do filme é calcada nessa perseguição em planos-sequência, editados com jump-cuts, o enredo do filme é composto por eventos que não se amarram de forma fechada, gerando no espectador a necessidade de construir as motivações dos personagens a partir de atos plenos de ambiguidade. No entanto - ou justamente por isso - $O$ Filho tem dois dos melhores e mais complexos personagens da cinematografia contemporânea, dando a seus espectadores uma das mais interessantes experiências de inferir "como é" viver a estranha situação por que passam.

Outro filme cujos expedientes visuais e narrativos heterodoxos nos chamam a atenção é Dez (2002), de Abbas Kiarostami. Muito embora, até onde se saiba, o filme não seja fruto da influência de nenhuma experiência com videogames, trata-se de uma construção muito particular, que remete a uma ecologia narrativa audiovisual que não pode ser pensada sem os games. O filme inteiro se passa dentro de um automóvel em fluxo pela cidade e o enredo se constrói a partir dos diálogos entre os passageiros do carro. Como se passa na vida, esses diálogos são cheios do que estamos chamando de "tempos mortos", ou seja, são cheios de idas e vindas, hesitações, repetições, vazios e outras marcas do Acaso na produção desse acontecimento. Kiarostami usou o carro como uma espécie de dispositivo narrativo para criar situações de confronto, filmandoas em planos fixos, com ação improvisada, o que acarreta essa pulsão de acontecimento espontâneo. A particularidade do dispositivo é circunscrever as possibilidades para, dentro dessa circunscrição, promover a emergência de acontecimentos não roteirizados - outra particularidade que nos remete à narrativa dos games. 


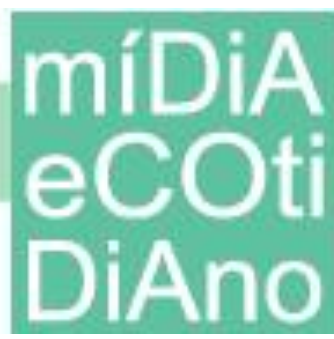

Podemos também citar o filme O Céu de Suely (2006), do brasileiro Karim Aïnouz, como parte dessa ecologia de construção de personagens cuja relação com o ambiente é extremamente importante. Nele, o que se vê na tela é fruto de um processo de imersão do elenco durante 3 meses na pequena e empobrecida cidade de Iguatu, no sertão central do estado do Ceará, para que pudessem criar seus personagens. Durante o tempo de preparação, atores e atrizes moraram nas casas de seus personagens, vestiram suas roupas, conviveram incógnitos com seus vizinhos, enquanto iam construindo os personagens com a ajuda de uma preparadora de elenco. A ideia por trás dessa imersão radical não era a descoberta de algo mais autêntico ou verdadeiro, mas a possibilidade de que, a partir da convivência com a miríade de informações contida no ambiente, pudesse emergir, na subjetividade dos atores e atrizes, outros sentimentos e emoções, aos quais não teriam acesso caso se preparassem no mesmo ambiente urbano em que vivem. Em outras palavras, a preparação de elenco proporcionou aos indivíduos um tipo de imersão análoga àquela que o game dá a seus jogadores - guardadas as devidas proporções - buscando extrair dessa experiência narrativa o sentimento de "como é" viver sob aquelas condições. Não a toa, no filme, a cidade tem a importância de um personagem e os personagens, de tão sofisticados, são o próprio filme, ficando os acontecimentos maiores do enredo em segundo plano.

\section{Conclusão}

Seria possível apontar ainda outros diálogos entre games e cinema. Os exemplos são muitos, variados e, no momento exato em que escrevemos, certamente surgem influências mútuas, que abrem outras perspectivas de análise. Mais do que mapear esses objetos individualmente, o que nos parece estar no coração do diálogo entre cinema e games é a notória emergência dessa ecologia maior, que, aos poucos, expande nossa própria definição de forma narrativa audiovisual. Os games e filmes que apontamos vêm tentando explorar propriedades que ressignificam a narrativa como uma forma de dar sentido à experiência do vivido, num mundo infinitamente mais complexo do que aquele onde surgiu a narrativa oral ou mesmo a cinematográfica. A matriz narrativa, assim, longe de estar engessada em formas que não dialogam mais com o mundo ao seu 
redor, segue problematizando a experiência do homem na sociedade, razão primeira de sua existência. Desta forma, se, por um lado, é clara a influência do cinema sobre os games, desde Myst e Doom, como já apontamos, é justamente o caminho oposto, a influência dos games sobre cinema, o que nos parece comprovar a importância dos games naquilo que podemos, talvez, chamar de uma subjetividade narrativa contemporânea. De forma análoga ao que Umberto Eco apontava na influência do expediente da transmissão ao vivo na TV para a narrativa do cinema moderno (ECO, 2003), parece-nos impossível pensar a proeminência no mundo contemporâneo de filmes de "narratividade difusa" sem considerar a contribuição dos games na grande ecologia de "tempos mortos" que cria o universo de expectativas das subjetividades narrativas do mundo atual. A partir disto, a questão que se coloca para pesquisas futuras é se os games, em seus gêneros mais hegemônicos, continuarão esse percurso que, de tão potente, transborda para outras mídias, ou se confirmarão a tendência que parece se descortinar com cada vez mais força, de engessamento de suas narrativas em prol da manutenção de franquias, deixando apenas aos formatos independentes a inovação dessa criação de espaço-tempo a que chamamos ainda de narrativa.

\section{Referências}

AARSETH, Espen J. Quest Games as Post-Narrative Discoruse. In: RYAN, MARIE-LAURE (Org.). Narrative across Media: the Languages of Storytelling. Lincoln, London: University of Nebraska Press, 2004. p. 361-376.

BRAMWELL, Tom. Heavy Rain's vital statistics. Games. Disponível em: <http://www.eurogamer.net/articles/heavy-rains-vital-statistics-blog-entry>. Acesso em: 29 jan. 2011.

BRUDVIG, Erik. Avatar: The Game Review. IGN. [S.l: s.n.]. Disponível em: <http://www.ign.com/articles/2009/12/01/avatar-the-game-review-2>. Acesso em: 8 dez. 2016, 1 dez. 2009

DARLEY, Andrew. Cultura Visual Digital: Espectaculo Y Nuevos Generos En Los Medios De Comunicacion. Barcelona: Paidos Iberica, 2000.

ECO, Umberto. Obra Aberta: Forma e Indeterminação nas Poéticas Contemporêneas. 9 ed. São Paulo: Perspectiva, 2003. (Coleção Debates).

GADAMER, Hans-Georg. Verdade e Método: Traços Fundamentais de Uma Hermenêutica Filosófica. 4 ed. Petropolis, RJ: Vozes, 2002. (Pensamento Humano, 16).

GIBSON, James J. The Ecological Approach to Visual Perception. Hillsdale, NJ: Lawrence Erlbaum Associates, 1986. 
GOMES, Renata. O design da narrativa como simulação imersiva. In: LEMOS, ANDRÉ; BERGER, CHRISTA; BARBOSA, MARIALVA (Org.). Livro da XIV Compós - 2005: Narrativas Midiáticas Contemporâneas. Porto Alegre: Sulina, 2006. p. 69-81.

HERMAN, David. Basic Elements of Narrative. Oxford: Wiley-Blackwell, 2009.

MURRAY, Janet Horowitz. Hamlet No Holodeck O Futuro da Narrativa no Ciberespaço. São Paulo: UNESP, 2003.

OLIVER, Julian Holland. Polygon Destinies: The Production of Place in the Digital RolePlaying Game. In: I INTERNATIONAL CONFERENCE ON COMPUTATIONAL SEMIOTICS FOR GAMES AND NEW MEDIA, 2001, Amsterdam. Anais... Amsterdam: [s.n.], 2001. Disponível em: <http://www.cosignconference.org/downloads/papers/ oliver_cosign_2001.pdf $>$.

ONG, Walter J. Oralidade e Cultura Escrita a Tecnologização da Palavra. Campinas, SP: Papirus, 1998.

PEARY, Gerald. Gerald Peary - interviews - Gus Van Sant - Elephant. Disponível em: <http://geraldpeary.com/interviews/stuv/van-sant-elephant.html>. Acesso em: 4 fev. 2011.

RYAN, Marie-Laure. Towards a definition of narrative. The Cambridge Companion to Narrative. Cambridge Companion to Literature. Cambridge: Cambridge University Press, 2007.

SANTAELlA, Lucia. Matrizes da Linguagem e Pensamento: Sonora Visual Verbal. São Paulo: Iluminuras/Fapesp, 2001.

VANORD, Kevin. James Cameron's Avatar: The Game Review. Disponível em: <http://www.gamespot.com/reviews/james-camerons-avatar-the-game-review/1900-6241883/>. Acesso em: 8 dez. 2016. 